\title{
DE LÁ PARA CÁ: CLASSE, RAÇA E GÊNERO EM NARRATIVAS AUTOBIOGRÁFICAS DE ANTROPÓLOGAS EM MEMORIAIS ACADÊMICOS (USP/UNICAMP, 2004-2014)
}

Wilton Carlos Lima da Silva $ه$

Rafaela Duarte Vieira (D) 


\section{RESUMO}

Nas universidades brasileiras, os memoriais acadêmicos são documentos que apresentam uma autorreflexão sobre a trajetória intelectual e profissional de um docente, caracterizando uma das raras manifestações de escrita autobiográfica a respeito de intelectuais e de pesquisadores de diferentes áreas, formações e pertencimentos. Este artigo apresenta reflexões sobre a percepção de classe, raça e gênero, a partir de relatos autobiográficos dos memoriais de titularidade de antropólogas da Universidade de São Paulo (USP) e da Universidade de Campinas (UNICAMP), aprovadas em concursos entre 2004 e 2014. Para o docente, este é um momento que representa a ascensão ao topo da carreira. No entanto, a universidade é uma instituição na qual as mulheres ainda lutam para superar preconceitos, por isso tais narrativas autorreflexivas estão inseridas em certas estruturas e tradições do campo intelectual-acadêmico e mostram-se como um rico material para a compreensão da trajetória e do papel feminino neste espaço, enquanto um exercício de autoetnografia.

Palavras-chave: memoriais acadêmicos; autoetnografia; antropólogas.

\section{FROM ONE TIME TO ANOTHER: CLASS, RACE AND GENDER IN AUTOBIOGRAPHICAL NARRATIVES OF ANTHROPOLOGISTS IN ACADEMIC MEMORIALS (USP/UNICAMP, 2004-2014)}

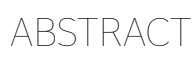

In the Brazilian public university, the academic memorials are documents that presents a self-reflection on the intellectual and professional trajectory of a professor, characterizing one of the rare manifestations of autobiographical writing of the intellectuals and researchers from different areas and formations. This article presents reflections on the perception of class, race and gender, based on autobiographical narratives of the memorials held by anthropologists of University of São Paulo (USP) and University of Campinas (UNICAMP), approved in contests between 2004 and 2014. For the professor, this is a moment that represents the rise to the top of the career. However, the university is an institution in which women still struggle to overcome prejudices, so these self-reflexive narratives are embedded in certain structures and traditions of the intellectual-academic field and are shown as a rich material to understand the trajectory and the feminine role in this space, as an exercise of autoethnography.

Keywords: academic memorials; autoethnography; women anthropologists
DE ALLÁ PARA ACÁ: CLASE, RAZA Y GÉNERO EN LAS NARRATIVAS AUTOBIOGRÁFICAS DE ANTROPÓLOGAS EN MEMORIALES ACADÉMICOS (USP/UNICAMP, 2004-2014)

En la universidad pública brasileña, el memorial académico es un documento que presenta una autorreflexión sobre la trayectoria intelectual y profesional de un profesor, coonstituyendo una de las raras manifestaciones de la escritura autobiográfica de intelectuales e investigadores en diferentes áreas, formaciones y departamentos. Este artículo presenta algunas reflexiones sobre clase, raza y género a partir de informes autobiográficos de los memoriales de antropólogas de la USP y la UNICAMP, entre 2004 y 2014. El memorial marca el punto más alto de la carrera universitaria de un profesor. No obstante, la universidad es una institución en que las mujeres aún luchan por superar los prejuicios. Tales narrativas autorreflexivas están dentro de ciertas estructuras y tradiciones del campo intelectual-académico y en la tradición antropológica, mostrándose como un material rico para entender la trayectoria y el papel femenino en este espacio, como un ejercicio de autoetnografía.

Palabras clave: memorias académicas; autoetnografia; antropólogas 


\section{INTRODUÇÃO}

Dentro da composição burocrática dos documentos das carreiras universitárias, os memoriais acadêmicos constam como uma fonte de pesquisa privilegiada, tanto por haver número restrito de narrativas autobiográficas dos docentes quanto por se configurarem como o relato de uma trajetória profissional e pessoal daqueles que desejam alcançar os maiores cargos, refletindo personalidades de seus pesquisadores e professores, assim como estruturas e funcionamentos institucionais das universidades brasileiras.

Por meio deste documento burocrático, os relatos dos pesquisadores nos interessam enquanto espaço de memórias pessoais, íntimas, coletivas, públicas e privadas, e, em particular, na dimensão da experiência de classe, raça e gênero, entre mulheres que atingiram o topo da carreira docente através da aprovação em um concurso de titularidade, tomando como base experiências de mulheres aprovadas na Universidade de São Paulo (USP) e na Universidade Estadual de Campinas (UNICAMP) entre os anos de 2004 e $2014^{1}$.

As questões identitárias, neste artigo, são apontadas a partir de vestígios de memória autobiográfica feminina, no interior de uma instituição cuja estrutura ainda apresenta características relevantes de elitismo, tradicionalismo, misoginia e patriarcalismo. Acreditamos que, no futuro, caso sejam estabelecidos processos de abertura dos quadros superiores da universidade a uma sociedade mais plural, serão possíveis os desdobramentos de outros estudos com as mesmas fontes, buscando trazer resultados mais amplos e diversos.

\section{MEMORIAL ACADÊMICO: MEMÓRIA INSTITUCIONAL E MEMÓRIA INDIVIDUAL}

Os professores produzem significativa documentação ao longo de suas carreiras, importantes vestígios para a construção e a reflexão sobre a memória universitária brasileira. Todavia, tais documentos, como atas, programas, livros, cadernos e diários de campo, entre outros, ainda não ocupam um espaço específico nos arquivos universitários, ficando distribuídos em salas, depósitos ou bibliotecas pessoais, o que dificulta a pesquisa que se destina a enfocar outros tipos de fontes não convencionais.

Devido à sua função institucional, essas fontes caracterizam-se como egodocumento/ autodocumento, ou seja, como documentos corporativos com narrativas que possuem como ponto de partida a manifestação da individualidade e que podem ser vistos como reflexos das relações coletivas, de valores, de mentalidades e da dinâmica existente entre a instituição e o indivíduo.

Assim, aqui nos propomos a ler e a mapear memoriais acadêmicos, documento exigido nos concursos para ascensão profissional nas universidades públicas brasileiras, e que se caracterizam tanto por apresentar uma estrutura burocraticamente determinada quanto uma dimensão autobiográfica/memorialística, de acordo com as escolhas narrativas de seus autores. O recorte escolhido privilegia a questão das percepções sobre a condição de classe, de raça e de 
gênero entre antropólogas que, como dito, atuam como professoras e pesquisadoras em duas das maiores e mais importantes universidades do país, Universidade de São Paulo (USP) e Universidade Estadual de Campinas (UNICAMP), entre 2004 e 2014, em seus memoriais de titularidade, o mais alto nível da carreira universitária.

Enquanto narrativa, a situação na qual narrador e personagem são a mesma pessoa assinala a presença do "pacto autobiográfico" (Lejeune 2008:48), no qual a confluência entre narrador e personagem busca construir um "relato retrospectivo em prosa que uma pessoa real faz de sua própria existência, enfatizando sua vida individual e, em particular, a história de sua personalidade" (Lejeune 2008:48).

No caso particular do memorial acadêmico, o pacto realizado com o leitor é iniciado antes mesmo da escrita, uma vez que, por ser um critério adotado para seleção em concurso, espera-se que o candidato desenvolva um texto sólido e verdadeiro sobre sua trajetória intelectual e profissional. Essas narrativas, todavia, também contam com outras formas de explicar as "verdades" expostas, a exemplo de recursos como citações e paráfrases ou mesmo apresentação de documentos oficiais, como currículos, cartas, fotografias, entre outros.

Ao observar esses relatos que expressam espaços individuais e coletivos, buscamos pensar o desenvolvimento de marcadores discursivos sobre a condição feminina nessas trajetórias. E, para conseguir refletir sobre esta temática, é necessário tanto ler aquilo que foi explicitado na narrativa como interpretar os silêncios e as lacunas que são mais expressivos nas relações familiares, corporais e psicológicas, entre outras possíveis dimensões ao longo de tais carreiras.

Os memoriais que temos como fonte de estudo neste artigo originam-se de duas instituições com políticas bastante distintas em relação ao cuidado com essa documentação: no caso da Faculdade de Filosofia, Letras e Ciências Humanas da USP, após os concursos de ascensão profissional, os memoriais são arquivados no Centro de Apoio à Pesquisa "Sérgio Buarque de Holanda"; enquanto no Instituto de Filosofia e Ciências Humanas da UNICAMP, tais documentos eram vistos apenas como um apenso aos processos, sendo descartados após o resultado.

Câmara \& Passeggi (2012) apontam alterações nas estruturas formal, estética e textual dos memoriais, que são documentos utilizados desde o surgimento da documentação no Brasil até o presente momento. Segundo Silva (2015, 2017), tais modificações acompanharam os processos de estruturação administrativo-burocrática da universidade no país e refletiram, ainda, debates teóricos e metodológicos nas ciências humanas em um contexto em que a figura do selfé evidenciada como somatória de experiências.

Ainda segundo Câmara \& Passeggi (2012), a historicização dos memoriais acadêmicos no país permite identificar: um momento inicial, entre 1930 e 1950, marcado por um processo de institucionalização e que apresenta os primeiros documentos desta natureza, concebidos como modelos com construção rígida e que mesclavam dados pessoais e profissionais; enquanto na fase seguinte, de 1950 a 1970, de consolidação, a estrutura se aproxima daquela que caracteriza o curriculum vitae, com dados de identificação e 
enumeração de realizações; e, finalmente, desde 1970, o período de diversificação, no qual há uma ampliação do espaço autobiográfico, com a valorização da escrita autodiegética.

Os estudos que buscam compreender essas relações, hoje, feitos com base no espaço da universidade só se tornaram possíveis a partir da década de noventa, quando se registram pesquisas que buscam entender como os professores universitários escrevem sobre as suas próprias trajetórias dentro e fora das universidades, qual a importância dos arquivos deixados por esses professores, os quais são, ainda, acompanhados da construção de uma perspectiva sobre a história do trabalho, que utiliza relatos orais e registros escritos.

Quando nos restringimos mais em relação ao grupo de disciplinas e de formação desses profissionais, percebemos que o número de trabalhos e de grupos de estudos voltados para essa temática ainda é pouco, e que a profissionalização e as escolhas de carreira no campo das ciências humanas, em geral, e em especial utilizandose de tal fonte, ainda não são suficientemente pesquisadas.

Em contraste com a relativa pouca atenção despertada pelos memoriais acadêmicos, em sua diversidade, quer pelas escolhas do narrador, quer pelo ethos da área e do grupo no qual ele se insere, neste tipo de documento são apresentadas valiosas informações sobre os docentes, não só enquanto professores e pesquisadores, mas também como indivíduos e membros de grupos, permitindo a delimitação de origens sociais (dinâmicas familiares, posições no núcleo familiar, redes de sociabilidade, ocupações e rendas, locais de residência, genealogia, entre outros), de educação familiar e formal (processos de alfabetização e formação intelectual, atividades de lazer e culturais, viagens diversas, domínio de idiomas, panteão cultural, artístico e intelectual, esperanças subjetivas, alternativas de carreira, modelos de excelência, percepções de desempenho etc.), de trajetória social (vida afetiva, casamento, dados sobre o cônjuge e sua família, capital material, entre outros) e da trajetória intelectual em si (para além do currículo, incorporando não só a sucessão de empregos, realizações e inserção no campo, mas, ainda, escolhas, heranças, trocas e rupturas, representações sobre corpo, classe, gênero e raça, perfis de identidade e referências etc.).

No contato com tal documentação, deparamonos com dois grupos distintos de memoriais: um dos textos onde foram mais filtradas as informações sobre o espaço individual e coletivo, contendo uma escrita mais cartesiana, onde os aspectos mais explorados são voltados para as etapas e a trajetória dentro do ambiente universitário, e outro em que, através de uma escrita mais hermenêutica, com forte componente autobiográfico e memorialístico, os textos apresentam a carreira como entremeada com a experiência pessoal e as esferas políticas, culturais e sociais do período abordado.

Elaborar um memorial é, portanto, um processo exploratório de si, no qual se procuram os resquícios de um passado não muito distante, filtrando-se o que é mais ou menos importante para o momento, na busca por escrever um relato autobiográfico, que, por mais delimitado que seja pela burocracia das universidades, é sempre um processo de exposição pública e privada, muitas vezes representando uma luta consigo mesmo, 
gerando críticas e autocríticas sobre a formação individual e coletiva.

Portanto, embora o desenvolvimento de um texto autorreflexivo sobre escolhas e conquistas individuais possa ser visto inicialmente como algo fácil e simples, uma vez que, enquanto pesquisadoras, as autoras são bastante familiarizadas com a prática de expressar-se pela palavra escrita - e, no caso particular da Antropologia, por dever de ofício estão habituadas à construção de diários de campo, com reflexões sobre identidades e alteridades -, quando realizamos as primeiras leituras, percebemos o incômodo que escrever um relato autobiográfico pode gerar nessas professoras:

\begin{abstract}
Depois de escrever alguns livros e muitos artigos, parece fácil, à primeira vista, redigir umas poucas páginas sobre o próprio percurso intelectual. Pois não é. Antes de mais nada, é difícil reconstruir uma trajetória notando e alinhando continuidades. Soa estranho buscar coerência em decisões, muitas vezes, marcadas por embaraços contextuais, hoje um pouco distantes no tempo. Mais complicado, ainda, é perceber que o passado, no meu caso, é um tanto recente (Schwarcz 2004:3).
\end{abstract}

Escrever um memorial gera, para o autor, uma série de lembranças e de reflexões que, para alguns, resulta na simples descrição do Currículo Lattes e, para outros, em um texto autobiográfico/ memorialístico com o aprofundamento dos

horizontes passados e a atualização das novas perspectivas. Portanto, em sua dimensão narrativa, o texto não precisa se encaixar necessariamente em configurações cronológicas ou temáticas básicas, quando se pensa o desenvolvimento de uma vida e de uma carreira, podendo ser apresentado como um projeto de vida em andamento, onde cada escolha direcionou a novos caminhos nos horizontes acadêmicos e pessoais. Isso pode ser originado de narradores eufóricos ou contritos.

Encaixar lembranças, documentos e fotografias faz com que o narrador-personagem monte uma trajetória em forma de mosaico, onde algumas peças, por mais que haja sentido que estejam ali, já não se encaixam mais, visto que a distância entre o vivido e o lembrado, dentro de uma nova temporalidade, pode redimensionar ou reformular o passado. Por isso, encontramos inúmeras lacunas nos textos, principalmente quando a vida pessoal é focada ${ }^{2}$ :

Envelhecer - diz um dos personagens
de Guimarães Rosa - devia de ser
bom, a gente ganhando maior acordo
consigo mesmo". Quando li esta
frase pela primeira vez, ela passou
despercebida. No auge do "açoite
de viver", o assunto parecia distante
demais para me interpelar. Quando a
reli, muitos anos depois, foi como um
clarão que iluminou a noite. Não só
pelo ajuste sincrônico com a minha
própria experiência de envelhecimento,
mas, sobretudo, pela maneira de dizer e
revolvê-la na sintonia da concordância
consigo mesmo. Nela encontrei a chave

2 "A nossa experiência do presente fica, portanto, inscrita na experiência passada. A memória representa o passado e o presente ligados entre si e coerentes, neste sentido, um com o outro. [...] Claro que esta inserção da memória na experiência presente pode também ser a raiz da sua debilidade como fonte de conhecimento do passado" (Fentress \& Wickham 1992:39). 
para abrir a caixa-preta que é esta peça de linguagem chamada memorial (Pontes 2014:3).

Esse olhar retrospectivo é composto por inúmeros filtros, e o primeiro é o de que sua gênese se liga ao concurso. Logo, essa fonte não pode ser encarada como uma autobiografia, no sentido estrito do termo, mas também não pode ser vista apenas como um dado burocrático, pois busca marcar a individualidade do candidato. Portanto, é algo que se realiza no momento em que o pesquisador se destina a uma avaliação acadêmica, na qual as realizações nesta dimensão, se não dão início à narrativa, são as principais linhas de força do relato, sendo recorrente a abordagem cumulativa e teleobjetivada, contextualizando, dentro de tal perspectiva, as dificuldades, os pertencimentos, as rede de relações e as conquistas profissionais:

Qualquer trajetória intelectual envolve interesses, descobertas, desejos, paixões, empenho, avanços e recuos, interlocução, mudanças de rumo, retomadas de antigos trajetos e muito mais. Os interesses, inicialmente, podem não parecer muito claros e consistentes, mas aos poucos vão se delineando mais nitidamente. São muitas as atividades que vamos assumindo ao longo da vida e, quando vistas à distância, podem demonstrar uma coerência antes não imaginada. Os diferentes cursos realizados na graduação e na pós, cursos de pósdoutorado, diferentes atividades de pesquisa, os cursos ministrados, as atividades de orientação de alunos. É o esforço de reflexão para a redação do memorial que permitirá desvendar se há, efetivamente, consistência entre a formação teórica, a pesquisa e a docência, nas diferentes fases da vida acadêmica (Novaes 2010:3).

Ao optar por uma abordagem mais cartesiana, com maior proximidade com o modelo de curriculum vitae, o autor-narrador utiliza-se dos referenciais mensuráveis, como o discurso de um terceiro (o conjunto de instituições que legitimam os títulos, os prêmios e as métricas) que fale sobre sua trajetória, de modo que a quantidade de graus acadêmicos, de livros, capítulos, artigos e orientandos, por exemplo, diz mais sobre ele do que detalhes sobre as relações, qualidade dos trabalhos e esforço desenvolvido para conseguir tais feitos, que poderiam ser distorcidos pela pessoalidade.

De outra forma, ao incorporar a experiência, isto é, a dimensão vivencial, o processo de escrita reflete outro horizonte de expectativa, no qual o memorial é o resultado de um artesanato, uma lapidação através dos exercícios de lembrar, organizar e filtrar, utilizando mais do que a enumeração, mas a ficção, no sentido de contar uma história, e que permite incorporar referenciais para além do institucional.

Algo que se destaca nessa fonte é a possibilidade de escrever em primeira pessoa, recurso ainda pouco utilizado dentro do ambiente acadêmico, pois a impessoalidade da escrita seria uma marca de reconhecimento da construção coletiva do conhecimento e uma prova de objetividade. No entanto, mesmo que o "eu" faça uma entrada em busca de certa notoriedade, é recorrente que não se mantenha sozinho e se faça acompanhar de "outros", com referências e citações de autores acadêmicos ou literários, ou ainda de marcas de pertencimento, como as referências e notas de rodapé, enquanto são 
expostas mais vitórias e sucessos do que derrotas e desgastes de uma trajetória que se justifica e se sedimenta página após página.

Falta, porém, o principal. Sei que nenhum memorial resume o trabalho de uma vida, que mistura temas profissionais com aspectos mais ou menos pessoais. No meu caso, sempre quis fazer muitas coisas ao mesmo tempo. Esse não é necessariamente um bom modelo, ou nem ao menos constitui um modelo. E, talvez, a única maneira como aprendi a desenvolver meu oficio (Schwarcz 2004:75).

O processo de escrita dos memoriais, enquanto escrita de natureza autobiográfica e/ ou memorialística, intercala dimensões subjetivas e conscientes do narrador, de maneira que apresenta tanto lembranças quanto esquecimentos, propositais ou não, envolvendo situações com terceiros. O memorial acadêmico, portanto, é um vestígio de memória, individual e institucional, e representa também uma situação profissional e um pertencimento grupal:

\footnotetext{
Memória aqui entendida como fenômeno coletivo cuja consolidação e perpetuação não deriva automaticamente da existência e permanência de uma "comunidade afetiva", mas da participação ativa dos atores sociais que - através de estratégias, suportes e construções narrativas variadas intervêm no processo de constituição
}

e formalização das recordações. Tal processo implica, necessariamente, de forma mais ou menos consistente, apagamentos, adaptações, omissões e não-ditos, os quais, em determinados momentos, podem vir à tona na forma de "lembrança dissidentes" (Schmidt 2009:56).

O concurso de titularidade, do qual faz parte o memorial ${ }^{3}$, é visto como um dos últimos rituais de passagem no interior das instituições universitárias, e marca o fim de um ciclo. Todavia, ele não representa o encerramento da vida ou da carreira acadêmica, tornando-se algo inacabado dentro da sua própria finalidade, a exemplo dos relatos a seguir:

Fui promovida de Professor Assistente a Professor Associado MS5 no dia 03/01/2001, portanto, este relato enfoca mais especificamente minhas atividades a partir de 2001. No entanto, já que eu não compreendia bem o espírito de um memorial na última ocasião que redigi um, em 2000, julguei necessário apresentar um novo memorial abrangente. Para quem, como eu, a língua materna é o inglês, um memorial soa como algo apropriado apenas para os mortos (Lea 2010:2).

Mas este memorial marca uma identidade, sua feitura representa um ajuste de contas com o tempo e leva, assim, a uma identidade profissional,

3 Destaque-se a particularidade das universidades paulistas, nas quais existe o título de professor livre-docente, que antecede a titularidade e cujos procedimentos do concurso são muito semelhantes aos de titularidade, oferecendo a possibilidade de comparação entre os memoriais de professores que fizeram ambos os concursos e, assim, podem ter mantido ou alterado suas escolhas de forma e estilo e os conteúdos das narrativas. 
realizada, no limite, em conjunto e a partir de tantas colaborações. Nunca parei (deste modo) para repensar minha própria trajetória e lembrar dos colegas que estiveram ao lado. $\mathrm{Na}$ verdade, diria que foi minha trajetória que parou para que eu pudesse refletir sobre ela (Schwarcz 2004:75).

A busca por um acerto de contas com o tempo é mais presente nos memoriais com perspectiva hermenêutica, onde um jogo com os pontos negativos e positivos é desenhado na escrita, em uma tentativa de fazer um acordo com fatos que se passaram. No caso dos memoriais femininos, esta dimensão se faz de forma bastante recorrente.

Devido ao caráter público dos memoriais, notamos que certas marcas na narrativa são mais atenuadas do que outras. No caso das mulheres, percebemos que a condição de gênero e a posição social possuem um peso maior na escrita do texto do que a de raça, fazendo com que certas indagações surgissem e se colocassem como grande desafio: o que seria uma narrativa feminina? O que podemos considerar como uma marca discursiva da situação de classe ou da condição de gênero? Em que medida o silêncio sobre a questão racial é um componente geracional? Responder de forma definitiva tais questões, mesmo que seja algo possível, transcende os objetivos do presente artigo, mas referenciá-las permite mantê-las como um ponto constante de reflexão no trabalho com as fontes.

Um primeiro aspecto que se destaca é que todas as autoras-narradoras aqui abordadas têm origem social de classe média e alta, nenhuma é negra ou indígena, embora duas trabalhem com antropologia de grupos indígenas, e apenas uma delas teve as questões de gênero como ponto central em suas pesquisas.

O segundo aspecto refere-se ao fato de esses relatos contruírem uma determinada memória da universidade e de sua forma de institucionalização, além de serem documentos públicos. Quando tratam de dimensões pessoais, os documentos fazem referência à rede de relações nas quais o autor-narrador está inserido e permanece relacionado, o que pode influenciar na maneira como este - que aqui, em particular, trata-se de interlocutoras mulheres - poderia utilizar este espaço como algo "pessoal" o suficiente para referir-se às situações de exclusão, assédio, conflitos etc. ${ }^{4}$.

Portanto, mesmo com as modificações ocorridas e a abertura, com o passar dos anos, para o desenvolvimento de relatos mais pessoais, escrever sobre a condição de ser mulher na universidade e seus espaços ainda continua sendo difícil e, muitas vezes, visto como algo dispensável, pelo receio de provocar conflitos e preconceitos diversos.

4 Hipoteticamente, a grande vantagem do memorial de titularidade em relação ao de livre-docência é que, como este marca um apogeu de carreira, subentende-se que os vínculos de dependência e de subordinação sejam menores. É possível lembrar também da ideia de "horizontes de expectativa", embora os dois tipos de memoriais se refiram a uma história inacabada, relatando uma carreira em movimento, na qual o autor/personagem ainda está em suas atividades acadêmicas. Essa particularidade distingue, inclusive em conteúdos e formas narrativas, os memoriais de livre-docência, que retratam uma carreira em consolidação, dos de titularidade, que se assemelham ao coroamento do projeto de vida intelectual. 
É válido ressaltar que, na multiplicidade de narrativas presentes nos memoriais, há, em alguns momentos, uma perspectiva confessional e que isso representa um conjunto de significados:

\begin{abstract}
A confissão tornada pública atua de forma ambígua, tanto como gestão possível de realização pessoal quanto na forma de recalque de situações de extrema solidão. Busca-se no outro a identificação que lhe dá direito de pertencer a um grupo ou a uma tribo. Michel Maffesoli, um dos teóricos citados, reitera a tendência do procedimento autobiográfico diferente do simples narcisismo, ao defini-lo como narcisismo de grupo (Souza \& Passeggi 2008:32).
\end{abstract}

Os documentos localizam o indivíduo em um espaço de grupos onde se busca inserção ou demonstração de certo deslocamento, mesmo que menos aparente, através de críticas sutis ao departamento ou à administração, ao mesmo tempo em que percebemos que algumas temáticas seriam mais ou menos aceitas dentro dessa escrita, uma vez que o projeto de memória apresentado não representa apenas um indivíduo, mas também os seus pares, a quem o relato se destina.

Estruturar os memoriais atendendo ao objetivo de uma escrita pessoal, que busque contemplar as lutas íntimas, sociais, culturais e políticas, e, entre elas, as questões de classe, raça e gênero, tornase um desafio dentro dos próprios pré-requisitos burocráticos/administrativos apresentados pela formatação do edital, todavia, quando isso ocorre, quer de forma explícita quer nas entrelinhas, apresenta-se uma ampliação do valor documental desse material e a possibilidade de compreensão de aspectos importantes da memória desses atores, de seus grupos e de suas instituições.

Da mesma forma, Josso (1999) distingue as histórias de vida como "projeto de conhecimento" das histórias de vida "a serviço de projetos". No primeiro caso, o relato oral ou escrito tenta abranger a totalidade da vida em seus diferentes registros, bem como em sua duração, mas na maior parte das vezes dá-se o segundo caso, em que a história produzida pelo relato é limitada a uma entrada que visa fornecer o material útil a um projeto específico.

De acordo com Bueno (2006), inserimos o memorial acadêmico como um projeto específico, para além de outros tipos de memoriais, cujos objetivos são o reconhecimento dos relatos do sujeito e do ator reabilitado ou a consolidação de um instrumento de formação.

\section{O MEMORIAL ACADÊMICO COMO AUTOETNOGRAFIA}

Ao longo do século XX, as particularidades metodológicas da Antropologia, com a imersão cultural e os necessários diários de campo, colocam a discussão sobre autorreflexão e narrativa de forma precoce. Isto se relaciona com o aparecimento do neologismo "autoetnografia" e com os desdobramentos das questões da narrativa, da escrita de si e do fazer etnográfico.

A autoetnografia é uma metodologia estabelecida no campo da Antropologia Social, a partir do momento em que a experiência etnográfica é percebida como algo que vai além da coleta de dados, das constantes observações e das anotações descritivas, incorporando a 
particularidade do ser e do estar em campo, bem como preocupando-se com a maneira como foram estabelecidas as interações com os contextos socioculturais, enquanto uma experiência de aprendizagem, com desafios e soluções, falhas e sucessos, que seriam, assim, compartilhados através da escrita. Segundo Versiani $(2005)^{5}$, os processos autoetnográficos surgem como uma construção do indivíduo e com a produção de sua memória ou de concepções sobre si.

Através de processos físicos, como a escrita de diários de campo, registros fotográficos e gravações, ou processos relacionados ao sujeito observador/observado, há necessidade do autodistanciamento (Waizbort 1998), que agora acontece de forma intermediária, uma vez que o antropólogo analisa a sua própria trajetória em tempos diferentes. Assim, percebemos como as antropólogas entrevistadas, além das delimitações ou aberturas do concurso, buscaram se inserir em um espaço de produção onde o memorial é visto como um objeto de competição, aproximação ou igualdade entre os pares na profissão.

Ellis (2004) define a autoetnografia como a descrição e a análise sistemática da vivência pessoal (auto), que busca compreender a experiência cultural (etno), inserida em uma forma de pesquisa e de escrita (grafia), com ênfase no processo de autorreflexão, aproximando-se de características da autobiografia (escrita sobre o próprio passado) e da etnografia (estudo de práticas culturais) para a produção de descrições estéticas, evocativas e densas ${ }^{6}$.

Neste processo de contar-se, as autorasnarradoras têm percepção do ethos que se manifesta na permeabilidade entre as suas formações profissionais e a maneira como desenvolvem seu exercício de autorreflexão:

Empenhada no entendimento alargado de experiências sociais e simbólicas diversas, a etnografia só se realiza por meio da escrita e só se completa na escrita. Daí que não basta dizer que o real é sempre construído e que os sentidos são sempre negociados numa trama complexa de dispositivos de poder. É preciso descrever: mostrar como e de que forma, em que contextos, com que entonação e modulação de voz, se no público ou no privado, por homens ou por mulheres etc. Os tais dos "imponderáveis da vida social", que tanto encantam os antropólogos, precisam antes ser descritos. Descrever, escrever, inscrever. Etnografar. Grafar, grafia, escrita (Pontes 2014:7).

E, afinal, o que é o ofício do antropólogo, senão a busca da alteridade desse movimento que leva a procurar no “outro" o próprio "eu” e sua afirmação. Mais do que isso, a descoberta do "outro" e sua compreensão realiza

5 A origem do termo "autoetnografia", segundo Versiani (2005:97), ocorre na Antropologia a partir de textos de ReedDanahay, Phillipe Lejeune, Alice Deck e Mary Louise Pratt, como um desdobramento de discussões entre produção textual e subjetivação, nas quais são alguns exemplos significativos a coletânea "Writing Culture: the poetics and politics of ethnography” (1986), organizada por Clifford e Marcus, e os trabalhos de Michael Fischer sobre autobiografias étnicas.

6 Essa aproximação entre a autobiografia e a etnografia pode resultar em um amálgama de documentos impressos e/ ou audiovisuais produzidos por um pesquisador que pretende oferecer aos leitores uma escrita que incorpore "ação, diálogo, emoção, corporalidade, espiritualidade e um senso de autoconsciência” (Raab 2013:2). 
transformações no sujeito e em sua própria percepção. Por isso, talvez, a Antropologia nunca tenha primado por "falar sobre", mas, antes, por "falar com”. E, nesse sentido, este memorial é também um exercício de alteridade. Termino-o, de certa forma, "alterada", como se tivesse olhado de esguelha para mim mesma, e estranhando (Schwarcz 2004:75-76).

Acreditamos que tais questões, por porosidade ou capilaridade do campo intelectual, apresentamse na escrita dos memoriais das antropólogas analisados, quer por aproximação quer por afastamento.

Em tais textos, as autoras-narradoras reorganizam as instâncias dicotômicas sujeitoobjeto, através da inclusão explícita de suas personas como foco de análise, na qual, ao mesmo tempo em que a narradora produz uma manifestação discursiva em que se coloca em relação consigo mesma, esta é mediada pelas exigências da contratualidade, ou seja, pelas expectativas do possível auditório em relação ao discurso em primeira pessoa, como relato crítico de sua trajetória cultural e intelectual, assim como de suas expectativas profissionais e acadêmicas.

O corpo documental escolhido reúne quatro memoriais acadêmicos de titularidade, escritos por Lilia K. Moritz Schwarcz (2004) e Sylvia Caiuby Novaes (2010), da Universidade de São Paulo, e Vanessa R. Lea (2010) e Heloísa André Pontes (2014), da Universidade Estadual de Campinas.

Os memoriais, apesar de não possuírem um formato estético rígido, apresentam um padrão, delimitado pela normatização acadêmica, cujo texto é impresso em sulfite A4, com margens de
3 e 2,5 cm, em tipo Times New Roman ou Arial, tamanho 12, com espaço 2 ou 1,5, ocupando, em geral, cerca de quatro dezenas de páginas, sendo comum o uso de notas de rodapé. Nos documentos analisados, processos de estetização (como uso de imagens, utilização de textos literários, para além de tímidas e raras epígrafes, ou editoração do volume) ou mesmo maiores arroubos literários mostraram-se quase totalmente ausentes.

Mesmo sendo raros memoriais com processos de estetização, eles nos mostram uma nova forma de apresentar-se academicamente, uma vez que deve haver cuidado ao inserir fotografias e ir tecendo a narrativa através delas, ou, ainda, para a utilização de um poema como epígrafe do texto, bem como para a implementação de modificações que vão para além do conteúdo interno do memorial. Essas alterações passam pela escolha do material da capa, se algum dado imagético será incorporado, se essa imagem fará parte da narrativa de forma direta ou apenas de forma estilística, pela seleção quanto ao tamanho e à gramatura das folhas, ao tipo de encadernação, entre outras possibilidades. Quando nos deparamos com um memorial com tais modificações, ficamos surpresos com os cuidados estabelecidos por seu autor e nos perguntamos qual tipo de performance, legado ou competição que este tinha em mente, sendo, inclusive, comum que, além da própria banca, também outros professores consultem eventualmente os memorais de conhecidos para realizarem os seus.

Os memoriais em análise apresentam características individuais e coletivas bem delimitadas, a partir de suas falas, escolhas, justificativas, decisões, dinâmicas estabelecidas, 
objetos de pesquisa e ênfases, mais ou menos acentuados dentro da narrativa, em meio a dados formais que são expostos de forma mais objetiva, como as inevitáveis datas de entrada na universidade, conclusão da dissertação de mestrado e da tese de doutorado, realização de concurso e efetivação na universidade etc., delimitando campos geracionais amplos.

A descrição da identidade profissional docente é apresentada como a sequência de simultâneas fases, quase como algo ininterrupto e sem dificuldades, as quais vão além da esfera institucional. Nesta descrição, ainda na infância é construída uma base sólida, com aprovações escolares e familiares, e o processo posterior é descrito como fruto desse trabalho inicial e da rede de relações, que justificam o lugar alcançado.

As narrativas de natureza mais privada, como as considerações sobre familiares, a língua materna, as viagens realizadas, a infância, os casamentos, a maternidade, as intrigas, a corporalidade, os sonhos, a atuação política, entre outras, também referenciam certas dimensões geracionais, não tanto em termos cronológicos, mas de vínculos diversos, como convivência política, familiar e intelectual ${ }^{7}$.

O memorial de Heloísa Pontes (2014) possui 37 páginas de narrativa, com capa, sumário, notas de rodapé e foi impresso em folha sulfite, tamanho A4, encadernado em espiral. Apresenta uma abordagem fortemente hermenêutica, com reflexões sobre suas percepções pessoais, embora circunscritas ao campo intelectual. As notas de rodapé guiam o leitor a compreender algumas lacunas na narrativa principal ${ }^{8}$.

Por sua vez, a narrativa de Vanessa R. Lea (2010) apresenta 51 páginas, com capa, sumário, também impresso em folha sulfite, tamanho A4, encadernado em espiral, apresentando algumas tabelas que fazem referência quantitativa aos trabalhos de campo realizados no Brasil, assim como diagramas e tabelas sobre educação indígena e uma análise sobre modificações ortográficas em uma cartilha de alfabetização indígena.

O relato de Lilia Schwarz (2014) desenvolve-se por 76 páginas, sendo encadernado em capa dura, com páginas em sulfite, tamanho A4, apresentando 152 notas de rodapé, que dotam o texto de maior densidade descritiva9.

7 Comparando as carreiras das quatro professoras, por exemplo, em termos temporais, Sylvia Novaes formou-se em nível de graduação em 1971, Vanessa R. Lea em 1974, Heloísa Pontes e Lilia Schwarcz em 1980, e o ingresso no doutorado de Lea foi em 1986, de Novaes em 1990, de Schwarcz em 1993 e de Pontes em 1996. Por sua vez, se tomarmos o espaço entre o fim da graduação e a titularidade, Schwarcz levou 24 anos para completar tal percurso, Pontes, 34, Lea, 36, e Novaes, 39.

8 Todos os memoriais apresentam, além do texto, única parte que buscamos analisar, o Currículo Lattes do candidato ao concurso, atendendo a uma exigência para a inscrição, que consta dos editais, o que produz um volume maior de páginas.

9 No caso dos memoriais da USP, preservados no Centro de Apoio a Memória Histórica (CAPH), na Faculdade de Filosofia, Letras e Ciências Humanas, cabe destacar uma particularidade documental do material referente à existência das atas dos concursos de livre-docência e titularidade em muitos dos memoriais pesquisados, ou seja, um documento produzido pela banca examinadora que oficializa o resultado e que apresenta as notas obtidas, o tema exposto pelo candidato, o dia, a hora e o local em que o processo foi realizado, além de considerações breves sobre a tese e o memorial acadêmico apresentados. Tal documentação não estava presente em todos os memoriais catalogados, uma vez que ela não faz parte 
Finalmente, o documento de Sylvia Novaes (2010) tem 50 páginas e apresenta características de estrutura e forma idêntica aos dois anteriores, com a particularidade de que trechos do memorial de livre-docência foram copiados na íntegra para o texto da titularidade ${ }^{10}$.

\section{VESTÍGIOS DA CONDIÇÃO DE CLASSE, RAÇA E GÊNERO}

Como já afirmado, os memoriais apresentam distintas formas de narrar uma trajetória, que, esquematicamente, dividimos como cartesianas ou hermenêuticas, sendo uma característica recorrente, quase um "era uma vez", a contextualização do ingresso na vida acadêmica, o que pode se iniciar pela vida propriamente universitária ou se projetar para as origens familiares, que seriam um indicador de origem social e de condição de classe.

Entre os memoriais analisados no presente artigo, tal regressão temporal, embora tratada de forma diversa quanto à extensão e à profundidade, quase sempre mostra o que antecede a vivência acadêmica e apresenta indicações sobre as origens de classes médias ou altas das autoras-narradoras.

A exceção é Pontes (2014), cuja narrativa se inicia com o ingresso na universidade e os caminhos intelectuais possíveis, ao mesmo tempo em que minuciosamente detalha escolhas e desdobramentos que mostram uma abordagem subjetiva e autorreferente, omitindo as relações extra-acadêmicas, que não são nunca contempladas, deixando-nos sem maiores informações sobre o que antecede a vida universitária e o seu cotidiano.

Lea (2010:2-3), por sua vez, identifica a gênese de seus interesses acadêmicos na infância, quando morou em Liverpool, tendo grande proximidade com famílias de cônsules oriundos de países latinos, além da vivência compartilhada com estes na escola. Ela também se refere à sua primeira experiência de ensino, em Valência, na Espanha, aos 15 anos, onde deu aulas particulares de inglês e entrou em contato com a cultura da América Latina. A formação escolar é identificada por ela como um sólido alicerce intelectual e cultural, que definiu gostos, interesses e aptidões para a universidade, através do contato com uma cultura letrada e erudita:

do corpo narrativo do mesmo e não possui obrigatoriedade de ser entregue para arquivamento, mas, em alguns casos, encontrava-se inserida entre as páginas dos textos. Esse registro permitiria vislumbrar algumas relações acadêmicas e redes de vínculo que foram estabelecidas durante os anos de carreira universitária do docente, sendo que, em alguns casos, existem agradecimentos, elogios e demonstrações diretas de interação e de reciprocidade.

10 Não é um caso único e, na realidade, menos incomum do que se poderia esperar, sendo possível justificar isso por diferentes aspectos: o vivido é o mesmo, resultado de um passado que não mudará e, portanto, a repetição se justifica pela experiência passada ser a mesma; embora tenham uma dimensão pública, os memoriais não são entendidos pela imensa maioria dos candidatos como futuro objeto de leitura e análise posterior, mas como parte secundária de um todo que os supera em importância, ou seja, a trajetória e a obra, que podem ser comprovadas por pesquisas, cargos, publicações e outras realizações ao longo da carreira; ou, ainda, a banca, enquanto público-alvo, normalmente não leu o relato do concurso anterior e não terá motivos para cotejar os dois textos, mas somente apreciar aquele que se apresenta como prova de verdade, conforme o edital exige, entre outras possibilidades. 
contragosto. [...] Tive que esperar até treze anos de idade para começar a estudar espanhol, algo que ansiava fazer devido à minha convivência intensa com pessoas que falavam essa língua. Comecei a estudar francês aos onze anos de idade e pretendia estudar literatura francesa e espanhola na universidade. Em francês, eu tinha lido autores como Molière, Racine e Mauriac, além de muita poesia, e o currículo em espanhol incluiu Cervantes, Pio Baroja, de Lara, entre outros (Lea 2010:3).

Schwarcz (2004:3) não contextualiza sua origem familiar e sua infância, mas identifica o Colégio Vocacional ${ }^{11}$, no final da década de 1960 , durante sua adolescência, como o fator de estímulo para o desenvolvimento de certas habilidades e potencialidades ("na prática de seminários, nos trabalhos de equipe, conheci a lógica de 'participar' e entendi o que significava informar e formar" $)^{12}$, enfocando, no entanto, mais a estrutura, os conteúdos e os objetivos da formação escolar do que suas particularidades pessoais.

Finalmente, Novaes (2010:4) escreve uma introdução de duas páginas, com ponderações sobre a trajetória pessoal, o capital cultural já acumulado antes do curso universitário e a escolha pelas Ciências Sociais em um momento tenso da vida político-institucional do país, em 1968, sem referência às origens familiares, apenas mencionando a "formação pré-universitária em colégios leigos e particulares” (com citação nominal do tradicional colégio Dante Alighieri) e a enumeração de três anos de italiano, seis de francês e alemão e onze anos de inglês (com um intercâmbio de três meses nos Estados Unidos), assim como cursos de formação complementar de história da arte, fotografia e pintura, além da frequência a teatros, cinemas e exposições, que surgem como um alicerce cultural humanista.

Por diferenças de estilo ou geracionais, a questão da ditadura militar, dimensão estrutural na trajetória de todas elas e que poderia oferecer um forte referencial memorialístico, é apontada com variadas ênfases pelas quatro autoras: Pontes (2014) inicia o relato a partir de sua estada na universidade, de 1977 a 1980, quando o processo de abertura já estava em andamento, mas não toca no assunto; Lea (2010:6-7) só entrou em contato com o autoritarismo do regime quando decidiu se dedicar aos índios brasileiros, como objetivo de seu doutorado, na década de 1980, através das dificuldades em abordar o tema e de justificar

11 Colégios Vocacionais, também chamados de Ginásios Vocacionais, foram parte de um projeto pioneiro criado pela pedagoga Maria Nilde Mascellani, com seis escolas da rede pública paulista, entre 1962 a 1969, sendo uma delas localizada no bairro paulistano do Brooklin (as outras eram unidades em Americana, Batatais, Rio Claro, Barretos e São Caetano do Sul). Tais escolas apresentavam uma proposta pedagógica inovadora, com aulas ocorrendo em período integral, conteúdos amplos e métodos de ensino e de avaliação que enfatizavam a criatividade e a participação pessoal, assim como o desenvolvimento do pensamento crítico. Tal projeto, por sua dimensão crítica, foi encerrado, e alguns de seus professores foram perseguidos a partir do recrudescimento do regime militar.

12 "No entanto, depois de tantos anos, tendo a reconhecer que o Vocacional marcou opções futuras e me fez vivenciar e entender a importância da História. Não uma História fechada em datas, heróis e eventos; mas, antes, aquela que faz sentido na própria experiência pessoal. O passado é uma nação distante, diz o ditado; o fato é que, quando chegou a hora de escolher uma carreira, a Faculdade de História pareceu-me uma saída possível" (Schwarcz 2004:3). 
sua permanência no país, enquanto estrangeira; Schwarcz (2004:3) afirma que acompanhou, no final da década de 1960, "(quase de arquibancada) os anos da ditadura e da repressão", embora percebesse as perseguições através do afastamento inesperado de professores do Colégio Vocacional por conta de preferências políticas; e, por último, Novaes (2010), que, tendo se formado em 1971, traz de forma mais significativa as referências ao período ditatorial, inclusive porque seu objeto de estudo no mestrado foram os Bororos, e a questão indigenista sempre foi um campo de tensão entre a sociedade civil e os militares ${ }^{13}$.

A questão de raça, por sua vez, é algo inexistente e, infelizmente, ainda é uma ausência sentida em relação a praticamente todos os memoriais pesquisados por nós nas duas instituições, haja vista a ainda baixa representatividade de negros entre os professores universitários atualmente e, mais ainda, em períodos anteriores, nos quais políticas inclusivas não eram adotadas nem para o acesso à graduação pelas instituições de ensino superior. Com certeza, memoriais acadêmicos das décadas de 20 e 30 do século XXI oferecerão maior diversidade em relação às origens étnicas e raciais do que atualmente encontramos.

Por sua vez, a questão étnica também aparece pouco, pois, nos casos aqui analisados, a origem judaica de Schwarcz não recebe nenhuma referência e a herança britânica de Lea somente é identificada no início do texto, por suas recordações de infância e formação, sendo de alguma forma repudiada, quando pede naturalização brasileira ${ }^{14}$.

Conforme já apontado anteriormente, a questão de gênero apresenta-se como um enorme desafio para ser utilizada como marcador discursivo, justamente na tentativa de delimitação daquilo que seria exclusivo da condição feminina e, mais ainda, como indicador legítimo de uma tradição misógina dentro do campo intelectual.

Por outro lado, referências ao feminismo ou à forma como a questão de gênero impactou as pesquisas desenvolvidas pelas autoras-narradoras, se não são uma recorrência, também não constituem uma ausência ${ }^{15}$.

13 "Durante os anos 70 as sociedades indígenas começam a se fazer cada vez mais presentes no cenário nacional. O modelo de desenvolvimento econômico imposto pelo governo militar a partir de 1964 afetara seriamente estas sociedades, cujos territórios foram atravessados por rodovias, inundados por represas, invadidos por projetos que ignoravam sua existência e em nada as beneficiava. Se até a década de 70 as notícias sobre os índios nos grandes jornais ocupavam as páginas dedicadas às espécies em extinção da fauna e da flora, a partir de então estas notícias passam a ocupar as páginas de política nacional, ao lado daquelas sobre a organização do movimento dos posseiros, a greve dos boias-frias, os movimentos sociais na periferia das grandes cidades. A 'abertura política' que se inicia na década de 80 abre espaço para a reorganização de diferentes segmentos da sociedade civil. Entidades de apoio à luta indígena são organizadas nos grandes centros urbanos já no final da década de 70" (Novaes 2010:10-11).

14 "Em 2005 naturalizei-me brasileira mais por minha indignação com a invasão do Iraque pela Inglaterra do que por acreditar que esse ato modificaria minha vida no Brasil” (Lea 2010:6).

15 "Um tema que me acompanha desde a chegada ao Museu Nacional, conforme já mencionado, é a questão de gênero. Na UNICAMP me beneficiei da possibilidade de apresentar dois trabalhos no Núcleo de Estudos Pagu, onde pude contar com Marisa Correia e Adriana Piscitelli como interlocutoras. Publiquei um primeiro artigo sobre gênero feminino nos Cadernos Pagu, em 1994, e outro na Revista de Estudos Feministas, em 2000. Publiquei um artigo sobre 
De certa forma, optamos, a partir das características das fontes, por uma percepção binária da memória evocada em relação aos papéis socialmente validados como masculino e feminino, assim como identificamos uma redução significativa da dimensão físico-corporal à possível referência à existência de filhos, mas ao completo silêncio sobre o sexo, a doença ou a morte em tais relatos.

Observamos que muitas vezes o que define essa dimensão binária, fundada nas tradições sociais, presente nos relatos, em relação aos femininos não é uma crítica expressa ou um relato detalhado sobre alguma situação que teve imposição direta pela condição de "ser mulher", mas sim uma falta nos masculinos sobre determinados aspectos da trajetória pessoal como os filhos, os casamentos ou as separações como temas sobre os quais os homens em geral calam, enquanto as mulheres eventualmente falam.

Assim, o que nos orientou foi escolher vestígios de memória do que observamos ser narrado e cobrado em nossa sociedade de forma distinta para homens e mulheres, mesmo quando possuem profissões semelhantes, levando em consideração que as narradoras nasceram entre as décadas de cinquenta e sessenta.

A junção entre a herança social e a perspectiva profissional é apresentada em diversos momentos, como nessa descrição de Lea sobre seu contato com as hierarquias de gênero em uma tribo indígena brasileira:
Na minha pesquisa de campo a questão de gênero estava sempre presente. Ficava inconformada quando meu poderoso "pai" Raoni me despachava para a roça quando estavam acontecendo reuniões políticas importantes nos Postos da FUNAI [Fundação Nacional do Índio] e eu era impedida de ir junto. Apesar disso ele me levava à casa dos homens para ficar ouvindo a conversa dos velhos. Minha "mãe", a mulher dele, perguntava se eu tinha pênis quando ia à casa dos homens. Eu retrucava que não tinha pênis, mas tampouco filhos com quem ficar em casa de noite. Também afirmava que os chefes no meu país eram duas mulheres - a rainha Elizabeth e Margaret Thatcher (Lea 2010:14).

a performance do choro cerimonial, uma arte feminina, na revista Indiana, em Berlim, depois de apresentar o trabalho no Congresso de Americanistas no Chile em 2003. Retorno a esse tema num trabalho sobre a morte, apresentado no México e publicado num livro no Peru em 2007, além do capítulo de livro sobre uma aula de choro, já mencionado. Ainda ligado à questão de gênero, publiquei um capítulo de livro sobre a pintura corporal Mebengokre, executada pelas mulheres, e outro capítulo na primeira coletânea dedicada à questão da paternidade múltipla” (Lea 2010:41-42). Ou ainda: "Empolgada com a leitura de 'Orlando', de Virgínia Woolf - que confirmava mais uma vez, para mim, o vigor com que a literatura descortina dimensões ao mesmo tempo sutis e poderosas da vida social, tornando pálidas muitas das leituras feitas no curso de ciências sociais - formulei o projeto 'Literatura no feminino?'. A ideia era analisar a poesia de Adélia Prado à luz do debate que se travava na época sobre a existência ou não de uma escrita feminina. Desencadeado pela releitura de Clarice Lispector e pela entrada na cena política do final dos anos de 1970, dos então chamados novos movimentos sociais, entre eles o feminista, tal debate desaguava na discussão sobre as construções sociais do feminino e do masculino (gênero ainda não era um termo utilizado) e, por tabela e para resumir uma discussão interessante, na antropologia” (Pontes 2014:4). 
Isso também fica evindente no trecho em que Novaes identifica tensões derivadas da mesma questão:

Admitida, em 1972, para o programa de pós-graduação em Antropologia não tive dúvidas em optar pela etnologia, sob a orientação da Professora Thekla Hartmann... O tema era aquele que iniciara na graduação: examinar o grupo doméstico Bororo como esfera fundamental para se pensar a relação entre o público e o privado nesta sociedade, mas agora com um foco mais definido - estava interessada em entender melhor a perspectiva das mulheres. A literatura sobre os Bororo sempre foi das mais abundantes em termos de etnologia brasileira, mas intrigava-me o fato de todas as análises privilegiarem, com exclusividade, a perspectiva masculina, mesmo aquelas empreendidas por antropólogas (Novaes 2010:8).

Quanto ao feminismo, referências sobre o tema são bastante comuns, como objeto ou enquanto vivência e/ou influência, como nos excertos a seguir:

Os tempos eram diferentes: algumas colegas viravam feministas; outros militavam no movimento homossexual; outros, ainda, passavam a defender a preservação do meio ambiente. Eram muitos os elementos de dispersão e, em meio a tantas motivações de ordem diversa, fazer "política séria" e entender formas diversas de participação social eram parte da nossa agenda, que incluía ler os "clássicos" e experimentar os "novos clássicos”. Os grandes partidos já não respondiam tanto à imaginação, e nessa época os movimentos sociais despertavam a atenção para suas reivindicações. "Somos todos gays, lésbicas e negros”, dizia a faixa em frente ao Teatro Municipal, no ano de 1980, convidando todos a aderir às novas causas (Schwarcz 2004:4).

Comecei a pesquisar, em meio à extensa população de paquistaneses que mora em Manchester, uma organização feminista - Al Masoom, composta por mulheres muçulmanas que procuravam lutar contra a violência às mulheres e às crianças na Bósnia, arrecadavam fundos para a construção de um hospital no Paquistão e se articulavam em termos da política local de Manchester, procurando garantir os direitos do grupo étnico a que pertenciam. "Al Masoom, Wonder Women” foi meu primeiro vídeo. Procuro nele mostrar a força política e a sensualidade de mulheres que o ocidente só consegue ver como um grupo apático e subjugado (Novaes 2010:16).

O final da década de 1970, no mundo intelectual do Rio de Janeiro, foi também marcado pela explosão de interesse no feminismo. Três colegas da minha turma, Bruna Franchetto, Maria Laura Cavalcanti e Maria Luiza Heilborn, lançaram a revista Perspectivas Antropológicas da Mulher, e a questão de gênero era um assunto debatido diariamente. Dois fatos no meu passado já haviam me sensibilizado para essa questão. Minha avó materna me contou que, quando se casou, meu avô quebrou seu equipamento de retocar fotografias (sua profissão na época). A partir daí 
o único provedor era ele. E minha mãe reclamava que o pai dela não se preocupava com a educação dela, mas somente do irmão dela; ele acabou estudando em Ruskin College, Oxford, e era comunista (Lea 2010:13-14).

No caso de Pontes, cuja dissertação de mestrado, defendida em 1986, era sobre o SOS-Mulher e as práticas feministas ${ }^{16}$, as tensões entre militância e vida acadêmica são apontadas claramente:

Tendo iniciado a vida profissional com uma pesquisa de campo sobre o movimento feminista, do qual inicialmente participei como militante, me vi às voltas no decorrer da pesquisa com os problemas postos pela relação sujeito e objeto e com as dificuldades para traduzi-los em chave etnográfica. Para levar adiante a pesquisa fui me distanciado da militância, sob pena de não fazer nem antropologia nem política. No movimento feminista passei a ser vista como uma militante pela "metade", enquanto na academia, corria o risco de não ser reconhecida como pesquisadora por estar comprometida demais com o meu objeto. Para sair do impasse em que me vira colocada - o de estar em lugar algum, que é o mesmo que estar no pior dos mundos - tive que objetivar a minha própria experiência em conjunto com a experiência das militantes que eu pesquisava. Nesse esforço de objetivação e no compasso analítico que lhe confere forma e direção, fui me distanciando dos pressupostos e das motivações iniciais que me levaram ao feminismo, ao mesmo tempo em que procurava uma forma expressiva de apresentar a etnografia (Pontes 2014:12).

Se o feminismo, no qual as relações entre a persona militante e a intelectual são problemáticas pelas exigências distintas e eventualmente excludentes que possam apresentar, não aparece de forma direta nos relatos autorreflexivos aqui abordados, a identidade pessoal inevitavelmente é permeada por seus referenciais e mescla-se nas tramas do discurso.

Retomando a questão do binarismo nos discursos, a temática mais abordada nos memoriais femininos e a que menos é tocada nos memoriais masculinos é a maternidade e/ou a paternidade, sendo apresentada dentro da narrativa de inúmeras maneiras, utilizada como justificativa para entrada ou saída de emprego, fonte de inspiração ou item decisivo para escolhas na carreira ou, ainda, como suporte emocional fundamental.

Segundo Perrot (2007), a maternidade é vista como um marcador na identidade da mulher, mesmo quando não deseja ser mãe, pois estamos inseridas em um universo onde a mulher torna-se completa a partir do momento que gera alguém, já as figuras masculinas já nascem completas.

Para além da maternidade em si, temos todas as formas de trabalho informal que ela agrega,

16 “'Do palco aos bastidores: o SOS-Mulher e as práticas feministas contemporâneas', minha dissertação de mestrado e meu primeiro trabalho de fôlego, é uma tentativa de analisar o perfil e a ideologia do movimento feminista paulista, a composição de seu quadro de militantes, sua dinâmica e trajetória no cenário político brasileiro, assim como as representações e as formulações feministas sobre a então chamada condição feminina e suas implicações nas práticas políticas e culturais do movimento. Os dois primeiros capítulos apresentam uma análise do movimento feminista em São Paulo; os dois últimos constituem a etnografia do grupo SOS-Mulher" (Pontes 2014:13). 
observada como carinho, onde tempo, saúde, disposição, paciência são, em sua maioria, mais oferecidos pela figura materna. Dessa forma, conseguimos imaginar, portanto, porque nos memoriais femininos essa temática é pontual, enquanto nos masculinos não.

\begin{abstract}
Através deste grupo de mulheres fui convidada a ir ao Paquistão, onde ocorreria o casamento da filha de uma delas e para esta pesquisa obtive uma bolsa da ICCCR - International Centre for Contemporary Cultural Research. Os paquistaneses são extremamente hospitaleiros. Passei um mês, com minhas três filhas, hospedada na casa da avó da noiva e pude me exercitar na filmagem do ritual do casamento, constituído de várias fases, que se estendem por três semanas. Apesar do pouco tempo de contato com esta cultura, a experiência prévia em Manchester e, fundamentalmente, minha longa pesquisa de campo entre os Bororo - tempo suficientemente longo, mesmo que em diferentes períodos - foram estratégicos para que eu rapidamente conseguisse me adaptar à nova situação. Contribuiu também para isto o fato de ter levado minhas filhas (Novaes 2010:16).
\end{abstract}

Descrita de forma breve, observamos também como a questão do trabalho no âmbito privado é explorada e delineada nas entrelinhas do texto, apresentando uma dupla carga, que dificilmente existe para os homens, todavia, sempre buscando evidenciar que foi feito por cuidado/amor com o outro/outros. Um ponto importante a ser considerado é que a experiência do trabalho do lar, para essas mulheres, é diferente, pois elas estão inseridas em um grupo econômico diferenciado em nossa sociedade.

Ao observar a construção dessas trajetórias e realizar algumas comparações com os memoriais masculinos, percebemos como a escrita feminina é articulada por meio de um viés coletivo, enquanto a masculina, individual, sendo que as questões de gênero estão diretamente ligadas com essa escrita, uma vez que a rede de relações citada pelas mulheres nos memoriais inúmeras vezes vai além do espaço acadêmico.

Os relatos construídos por meio de uma linguagem coletiva estão mais inseridos nas questões familiares, segundo as quais parentes mais próximos surgem como agentes ativos em suas trajetórias, auxiliando em diversos momentos. Portanto, o memorial torna-se um espaço não só de retomada na trajetória, mas também de agradecimentos para essas pessoas que estiveram presentes na construção da vida privada e coletiva. Nos memoriais masculinos, por sua vez, agradecimentos desse tipo surgem, em sua maioria, apenas no espaço público, enquanto o privado fica como que esquecido ${ }^{17}$.

17 "Para Paul Thompson, há diferenças quando se enquadra o gênero na memória. Os homens têm uma tendência em falar da vida como sua, sendo os sujeitos de suas ações. Em contraposição, as mulheres utilizam verbalizações típicas, calcadas sobre as relações sociais ao incluir nas suas histórias de vida pedaços das histórias de outras pessoas, usando mais frequentemente o nós. Para as mulheres, são importantes as relações afetivas e humanas representadas por aquilo que elas construíram com os outros, o companheiro, os filhos, enquanto o homem centra-se nas suas realizações individuais. Thompson se refere àquilo que ele chama de processo terapêutico original mediante a liberação da memória, em que pelo fato de saber-se possuidor de algo que interessa ao outro (o pesquisador), o depoente (a pessoa idosa) 
Enquanto todas fazem referências a alguns professores, colegas de pós-graduação ou de departamento, Pontes (2014) e Schwarcz (2004) não citam nem seus companheiros ou filhos, Lea (2010), que se concentra quase totalmente na descrição minuciosa de suas atividades acadêmicoprofissionais, também faz rápidas referências à vida privada - como sobre a existência de um "companheiro" (Caio Navarro de Toledo) na descrição de sua defesa de doutorado (Lea 2010:18) ou menciona um afastamento da pesquisa de campo frente à sua gestação (Lea 2010:20) -, assim como Novaes (2010:16), que também identifica seu vínculo materno.

\section{CONSIDERAÇÕES FINAIS}

O memorial propõe ao autor-narrador um acerto de contas com o tempo, onde este escolhe quais pontos deseja demonstrar ao leitor, tendo a possibilidade de construir uma narrativa ampla, com reflexões sobre grandes feitos ou trivialidades, expressando o poder de escolha sobre a dinâmica do texto, que pode assumir uma dimensão mais cartesiana ou hermenêutica, embora não de forma estanque, no encontro entre a assertividade do concurso e a abstração da memória.

Por mais que o edital determine o que o documento deva conter - um texto que expresse de forma objetiva a trajetória intelectual e profissional -, não é estabelecido o que não pode constar, espaço que permite o exercício da narratividade, a inserção do subjetivo e a estetização da escrita, reafirmando a natureza dual desta fonte, que é tanto burocrática quanto pessoal.

A partir dessas narrativas, ainda muito pouco exploradas enquanto objeto de pesquisa, quer pelas chaves analíticas de classe, raça ou gênero, quer por outras abordagens, talvez seja possível a compreensão de diferentes concepções do "eu" e das formas como ele é inserido no espaço acadêmico e social.

Para além de traços de personalidade de cada uma e das escolhas narrativas feitas para a estruturação do documento, acreditamos que a experiência com o desenvolvimento da pesquisa de campo entre os índios e a utilização do inevitável "diário de campo" aproximam Novaes (2010) e Lea (2010) de uma escrita autorreflexiva ${ }^{18}$, que, mesmo quando se pretende objetiva, faz concessões ao íntimo e pessoal, enquanto Pontes (2014), que teve uma significativa experiência etnográfica no mestrado, a partir do doutorado optou por pesquisas mais bibliográficas e arquivísticas, assim como as de Schwarcz (2004). Embora não tenham tal referencial metodológico, estão ambas inseridas em uma geração na qual o giro linguístico

introjeta um sentimento de importância e renovação, de finalidade, de algo por esperar. A liberação da memória pode possibilitar a emergência de sentimentos poderosos funcionando como uma descarga emocional para alguém que há tempos não é mais ouvido. Falar sobre o passado significa rememorar alegrias, sucessos ou fracassos, perdas, dores, rancores mal resolvidos que adquirem nova significação no momento presente. Sempre é gratificante relembrar o que se foi e o que se realizou, apesar da carga de pesares que qualquer existência relativamente longa acumula" (Almeida 1998:54-55).

18 A temática da escrita autorreflexiva na antropologia e na pesquisa etnográfica já produziu uma ampla bibliografia (Green \& Vallat 1981; Clifford \& Marcus 1986; Erickson 1988; Clifford 2008), assim como as dores e as angústias da pesquisa em arquivo também originaram algumas reflexões bastante instigantes (Derrida 2001; Farge 2009). 
se apresentou de forma enfática, e cujos textos, inclusive, apresentam forte dimensão subjetiva, mas mais internalista. Acreditamos, portanto, que, embora se apropriem de formas distintas do ethos antropológico, se caracterizam por suas perspectivas pessoais como exemplos distintos de autoetnografia.

Assim resta, a partir de tais caminhos e possibilidades, problematizar sempre e mais tanto a escrita do campo quanto a grafia da vida.

\section{AGRADECIMENTOS}

O artigo é resultado de pesquisas realizadas com apoio de bolsas da Fundação de Amparo à Pesquisa do Estado de São Paulo (FAPESP), processos 2016/19014-0 e 2018/05783-7.

\section{REFERÊNCIAS}

Almeida, J. 1998. Mulher e educação: a paixão pelo possível. São Paulo: UNESP.

Bueno, B. O. 2006. Histórias de vida e autobiografias na formação de professores e profissão docente (Brasil, 1985-2003). Educação e Pesquisa 32(2):385410. DOI: http://dx.doi.org/10.1590/S151797022006000200013.

Câmara, S. C. X., e M. C. Passeggi. 2012. O gênero memorial acadêmico no Brasil: concepções e mudanças de uma autobiografia intelectual. Anais da fornada Nacional do Grupo de Estudos Línguístico Do Nordeste 24:1-12. Disponível em: http:// www.gelne.com.br/arquivos/anais/gelne-2012/ Arquivos/\%C3\%A1reas\%20tem\%C3\%A1ticas/ G\%C3\%AAneros\%20textuais/Sandra\%20e\%20 Maria\%20-\%20O\%20G\%C3\%8ANERO $\% 20$
MEMORIAL\%20ACAD\%C3\%8AMICO.pdf. Acesso em: 27 abr. 2014.

Clifford, J., e G. Marcus. 1986. Writing culture: the poetics and politics of ethnography. Berkeley, Los Angeles, London: University of California Press.

Clifford, J. 2008. A experiência etnográfica: antropologia e literatura no século XX. Rio de Janeiro: Editora UFRJ.

Derrida, J. 2001. Mal de arquivo: uma impressão freudiana. Rio de Janeiro: Relume Dumará.

Ellis, C. 2004. The ethnographic I: a methodological novel about autoethnography. Walnut Creek, California: Alta Mira Press.

Erickson, F. 1988. Ethnographic description, in Sociolinguistics: an international handbook of the science of language and society. v. 2. Editado por U. Ammon, N. Dittmar, K. Mathier, pp. 1081-1095. New York: Walter de Gruyter.

Farge, A. 2009. O sabor do arquivo. São Paulo: Edusp.

Fentress, J., e C. Wickham. 1992. Memória social: novas perspectivas sobre o passado. Lisboa: Teorema.

Green, J. L., e C. Vallat, 1981. Ethnography and language. Norwood, NJ: Ablex Press.

Josso, M.-C. 1999. História de vida e projeto: a história de vida como projeto e as "histórias de vida" a serviço de projetos. Educação e Pesquisa 
25(2):11-23. DOI: http://dx.doi.org/10.1590/S151797021999000200002 .

Lea, V. R. 2010. Memorial. Concurso de Professor Titular em Antropologia. Instituto de Filosofia e Ciências Humanas. Campinas: Universidade Estadual de Campinas.

Lejeune, P. 2008. O pacto autobiográfico: de Rousseau à internet. Belo Horizonte: UFMG.

Novaes, S. C. 2010. Memorial. Concurso de Professor Titular em Antropologia. Faculdade de Filosofia, Letras e Ciências Humanas. São Paulo: Universidade de São Paulo.

Perrot, M. 2007. Minha história das mulheres. São Paulo: Contexto.

Pontes, H. A. 2014. Memorial. Concurso de Professor Titular em Antropologia. Instituto de Filosofia, e Ciências Humanas. Campinas: Universidade Estadual de Campinas.

Raab, D. 2013. Transpersonal approaches to autoethnographic research and writing. The Qualitative Report 18(21):1-18. Disponível em: http://nsuworks.nova.edu/cgi/viewcontent. cgi?article $=1516 \&$ context=tqr. Acesso em: 16 mar. 2018.

Schmidt, B. B. 2009. Nunca houve uma mulher como Gilda? Memória e gênero na construção de uma mulher "excepcional", in Memórias e narrativas (auto) biográficas. Editado por B. B. Schmidt e A. C. Gomes, pp. 55-75. Porto Alegre/Rio de Janeiro: UFRGS/FGV.

Schwarcz, L. K. M. 2004. Memorial. Concurso de Professor Titular em Antropologia. Faculdade de Filosofia, Letras e Ciências Humanas. São Paulo: Universidade de São Paulo.

Silva, W. C. L. 2015. A vida, a obra, o que falta, o que sobra: memorial acadêmico, direitos e obrigações da escrita. Tempo \& Argumento 7(15):103-136. DOI: http://dx.doi.org/10.5965/2 175180307152015103.

Silva, W. C. L. 2017. Brilho etéreo de arquivos e lembranças: algumas questões sobre arquivos pessoais e biografias. Diálogos 21(2):32-43. DOI: http://dx.doi.org/10.4025/diálogos.v21i2.39526.

Souza, E. C., e M. C. Passeggi. 2008. Pesquisa (auto) biográfica: cotidiano, imaginário e memória. NatalSão Paulo: EDUFRN-Paulus.

Versiani, D. B. 2005. Autoetnografias: conceitos alternativos em construção. Rio de Janeiro: 7 Letras.

Waizbort, L. 1998. Para uma sociologia do memorial acadêmico - um fragmento. Revista de Teoria Literária e Literatura Comparada 3(3):7782. DOI: https://doi.org/10.11606/issn.2237-1184. v0i3p77-82. 